\section{A percepção de crianças cariocas sobre a pandemia de COVID-19, SARS-CoV-2 e os vírus em geral}

\author{
Perceptions of the COVID-19 pandemic, \\ SARS-CoV-2, and viruses in general \\ among children
}

La percepción de niños cariocas sobre la pandemia de COVID-19, SARS-CoV-2 y los virus en general
Carolina Habergric Folino 1

Marcela Vitor Alvaro 2

Luisa Massarani 3,4

Catarina Chagas 3 doi: $10.1590 / 0102-311 \times 00304320$

\section{Resumo}

Apesar de as crianças serem apontadas como o grupo menos afetado pelos sintomas da COVID-19, embora não ileso à doença e suas formas graves, seu cotidiano foi afetado de várias formas, incluindo a interrupção da vida escolar presencial e o contato com colegas de aula, além de impactos relacionados ao isolamento social e, em muitos casos, problemas financeiros e de saúde enfrentados por familiares. Neste trabalho, temos como objetivo compreender a percepção de crianças cariocas sobre o SARS-CoV-2, a COVID-19 e os vírus em geral, por meio de um estudo qualitativo. Entrevistamos 20 crianças por meio de plataformas de serviços de conferência. Os resultados indicam que elas estão conscientes dos riscos e cuidados necessários para a prevenção do coronavírus, mostrando-se apreensivas, com medo de pegar a doença e passar para os seus familiares. Quanto aos vírus em geral, observamos que suas percepções são relacionadas diretamente ao coronavírus, isto é, à situação com que estão lidando atualmente. O estudo traz subsídios que podem ajudar na concepção de estratégias de divulgação científica.

COVID-19; Coronavírus; Pandemias; Virus

\author{
Correspondência \\ L. Massarani \\ Instituto Nacional de Comunicação Pública da Ciência e \\ Tecnologia. \\ Av. Brasil 4036, Prédio da Expansão, sala 414, Rio de Janeiro, \\ RJ 21041-361, Brasil. \\ luisa.massarani6@gmail.com \\ 1 Fundação Oswaldo Cruz, Rio de Janeiro. Brasil. \\ 2 Instituto Nacional de Ciência e Tecnologia, Fundação Oswaldo \\ Cruz, Rio de Janeiro, Brasil. \\ 3 Instituto Nacional de Comunicação Pública da Ciência e \\ Tecnologia, Rio de Janeiro, Brasil. \\ ${ }_{4}$ Casa de Oswaldo Cruz, Fundação Oswaldo Cruz, Rio de \\ Janeiro, Brasil.
}




\section{Introdução}

Em 11 de março de 2020, a Organização Mundial da Saúde (OMS) declarou a COVID-19, causada por um novo tipo de coronavírus, o SARS-CoV-2, como uma pandemia ${ }^{1}$. No Brasil, o primeiro caso da doença foi registrado em 26 de fevereiro. Duas semanas depois, foram identificadas transmissões comunitárias em São Paulo e no Rio de Janeiro. Em 16 de março, o Governo do Estado do Rio de Janeiro reconheceu a situação de emergência na saúde pública e adotou uma série de medidas para o enfrentamento da propagação da doença 2. Atividades consideradas essenciais, como mercados e farmácias, continuaram funcionando, mas um decreto, em 16 de março, determinou a suspensão de atividades científicas, culturais e coletivas (museus, congressos, shows), da circulação de linhas interestaduais de ônibus e das aulas nas redes pública e privada 3 .

$\mathrm{Na}$ cidade do Rio de Janeiro, a prefeitura lançou um decreto, em 21 de março, determinando a adoção de medidas adicionais para o enfrentamento do novo coronavírus. O decreto determinava o fechamento das escolas municipais até o dia 12 de abril e anunciava o fornecimento de mil cestas básicas aos alunos da rede municipal com famílias hipossuficientes ${ }^{4}$. Em 1o de junho, a Prefeitura do Rio de Janeiro anunciou a retomada gradual das atividades econômicas da cidade, mas as escolas foram mantidas fechadas 5 , fazendo com que as crianças permanecessem em casa, longe dos amigos e do convívio social até o momento da coleta e análise dos dados (setembro de 2020).

Apesar de as crianças serem apontadas como o grupo menos afetado pelos sintomas da doença, embora não ileso à doença e suas formas graves, seu cotidiano foi afetado de várias formas, incluindo a interrupção da vida escolar presencial, impactos relacionados ao isolamento social e, em muitos casos, problemas financeiros e de saúde enfrentados por familiares. Nesse contexto, as crianças são um grupo sensível ao confinamento, com ameaças sérias à sua saúde, tanto do ponto de vista físico quanto do ponto de vista emocional 6,7. De acordo com alguns autores, é essencial que as crianças entendam o que está acontecendo no mundo, isto é, devem ser tão informadas quanto os adultos e outros grupos em geral sobre por que elas têm de ficar confinadas 8 .

Há vários estudos sobre a percepção de doenças infecciosas emergentes, no geral, e da COVID-19, especificamente 9,10,11,12. No entanto, a maior parte deles tem investigado adultos, deixando de fora as crianças ${ }^{13}$. Identificamos apenas uma pesquisa sobre a percepção de crianças acerca da pandemia do coronavírus 13. Realizado na Espanha, o trabalho evidenciou que as crianças têm enfrentado diversos desafios e são emocionalmente impactadas pela pandemia 13 .

\section{Estudos de percepção com crianças}

A partir da década de 1980, observou-se um número crescente, embora reduzido, de pesquisas dedicadas à percepção de crianças sobre o conceito de doença ou sobre o que significa estar doente 14,15,16. Essa literatura indica que as percepções das crianças afetam diretamente os seus comportamentos relacionados à saúde e à percepção do risco 17,18 .

Nesse sentido, compreender o que as crianças entendem por doenças, de modo geral, pode gerar bons resultados tanto de ordem prática quanto teórica 16 . Por exemplo, interessados no papel que as concepções de saúde e de doença de crianças e adolescentes desempenham como mediadoras de comportamentos, pesquisadores da área da saúde têm se dedicado a estas investigações visando a elaborar estratégias de promoção da saúde 19. Tais estudos também são úteis para elaborar explicações mais adequadas sobre as doenças para crianças de idades específicas, especialmente aquelas afetadas por determinadas enfermidades e que estão envolvidas nas decisões (de tratamento, por exemplo) que impactam suas vidas ${ }^{16}$. Isso porque, ainda que seus responsáveis tomem as decisões, conforme as crianças atingem níveis cognitivos mais avançados elas têm a capacidade de escolher ou rejeitar determinada opção de tratamento e, por isto, devem ser bem informadas sobre suas condições e possibilidades ${ }^{14}$. Nesses trabalhos, normalmente, enfoca-se no nível cognitivo das crianças, pois influencia diretamente a forma como o início, o desenvolvimento e o prognóstico de doenças pediátricas são relatados para e por elas.

Como exemplo da relação entre desenvolvimento cognitivo e sentidos atribuídos a doenças, há evidências de que as crianças mais novas tendem a acreditar que apenas pessoas ruins ficam doentes 14 . 
Estudos sobre percepção de saúde e doença com crianças e adolescentes, baseando-se na Teoria do Desenvolvimento de Piaget, também têm demonstrado que a percepção de saúde e doença pelas crianças tende a ser diferente em cada etapa do desenvolvimento 18,20,21,22.

Schmidt \& Frohling 23, ao estudar as percepções das crianças sobre o tema em cada faixa etária, identificaram que as definições de saúde mais adequadas englobam mais do que a "ausência de doença”. Também observaram que definições negativas - de ausência - tendem a escassear conforme a idade aumenta, e as definições mais elaboradas de saúde, destacando aspectos positivos como o humor, tornam-se mais comuns. Já o conceito de doença está frequentemente associado a sintomas e ao mal-estar 23 .

Millstein \& Irwin 19 analisaram os conceitos de saúde e doença, simultaneamente de 218 adolescentes, chegando à conclusão de que estes dois conceitos não são considerados extremos opostos de uma dimensão única, por exemplo, doença sendo considerada "ausência de saúde" e vice-versa. São conceitos diferentes que, em determinado ponto, se sobrepõem. Em contextos de doenças específicas, como o das doenças infecciosas emergentes, a Teoria das Representações Sociais também tem sido utilizada para a compreensão das formas pelas quais o conhecimento sobre um novo fenômeno de risco é transformado do discurso científico para a compreensão comum de pessoas leigas 13,24.

Diante da pandemia de COVID-19 e da relevância de pesquisas de percepção para a área da saúde, é importante identificar as formas pelas quais as crianças entendem essa crise de saúde pública, a fim de desenvolver estratégias e ferramentas comunicacionais, considerando suas preocupações 13 , percepções e seu entendimento sobre o vírus.

\section{Metodologia}

O objetivo geral deste trabalho é analisar a percepção de crianças cariocas sobre o SARS-CoV-2, a COVID-19 e os vírus em geral, com abordagem qualitativa. O estudo está inserido em um projeto mais amplo de percepção pública da ciência no Brasil e foi aprovado pelo Comitê de Ética da Escola Politécnica de Saúde Joaquim Venâncio, Fundação Oswaldo Cruz (Fiocruz - 866322218.2.1001.5241).

Realizamos 20 entrevistas com crianças entre 8 e 10 anos de idade, fase que faz parte do período das operações concretas, de acordo com a classificação dos níveis de desenvolvimento cognitivo de Piaget 25. No período operatório concreto, a mistura do real e do lúdico, nas explicações fornecidas pelas crianças, é substituída por uma necessidade de explicar logicamente suas ideias e ações, em uma atitude mais crítica 25. Para a escolha dos sujeitos do estudo, definimos como critério de inclusão residir no Município do Rio de Janeiro. Excluímos as crianças filhas de profissionais da saúde ou de cientistas.

Visando a diversificar o perfil das crianças participantes, entrevistamos 10 meninos e 10 meninas, de distintos bairros de residência e diferentes perfis socioeconômicos. Em relação aos perfis socioeconômicos, levamos em consideração o Índice de Desenvolvimento Social (IDS) da Região Metropolitana do Rio de Janeiro. O IDS é determinado com base no Censo Demográfico de 2010 do Instituto Brasileiro de Geografia e Estatística (IBGE) e leva em consideração dados referentes à coleta de lixo, abastecimento de água, esgoto adequado, taxa de analfabetismo, rendimento médio por domicílio, entre outros (Data Rio. Índice de desenvolvimento social da região metropolitana do Rio de Janeiro. https://www.data.rio/datasets/fa85ddc76a524380ad7fc60e3006ee97, acessado em 17/Out/2020).

Em respeito à recomendação de manter o distanciamento social, sempre que possível, durante a pandemia, não realizamos encontros presenciais com as crianças participantes. A identificação das crianças e o convite à participação na pesquisa foram por meio dos seus responsáveis, por correio eletrônico e WhatsApp. Uma mensagem apresentando a pesquisa era enviada aos responsáveis de potenciais participantes indicados por colegas, familiares e outros participantes, em uma abordagem semelhante à da "bola de neve" 26 . Todos os responsáveis responderam a um formulário online, criado na plataforma Google Forms (https://www.google.com/intl/pt-BR/forms/about/), com informações gerais, como data de nascimento das crianças, escola, profissão dos responsáveis e bairro de residência. Também buscamos identificar meios pelos quais os responsáveis se informam sobre a COVID-19 e a frequência com que buscam informações. 
Dentre os meninos entrevistados, cinco moram em bairros de IDS elevado, entre 0,773 e 0,667, estudantes de colégios particulares de grande porte, cinco em bairros com IDS entre 0,610 e 0,570, estudantes de colégios particulares de menor porte e da rede pública. Cinco meninas moram em bairros com IDS entre 0,780 e 0,659 e frequentam colégios particulares, apenas uma em colégio público federal. Outras cinco residem em bairros com IDS entre 0,643 e 0,540 e estudam em colégios particulares de bairro e colégios públicos. Assim, acreditamos haver equilíbrio entre as crianças cujas famílias encontram-se em situação de maior ou menor vulnerabilidade social frente à pandemia de COVID-19.

As entrevistas foram realizadas por meio das plataformas de serviços de conferência Zoom (https://zoom.us/pt-pt/meetings.html) e Google Meet (https://meet.google.com/), em comum acordo com a disponibilidade dos participantes, entre julho e agosto de 2020.

A entrevista foi semiestruturada, com roteiro dividido em três partes. A primeira tinha como objetivo conhecer as crianças. Mais do que trazer informações além das que os responsáveis nos tinham fornecido, essa parte do roteiro visava a deixar a criança mais à vontade, em uma situação em que ela conversava sobre assuntos que conhece bem. A segunda parte da entrevista era direcionada à realidade das crianças em tempos de COVID-19 e suas percepções sobre a doença. A parte final teve como objetivo conhecer a percepção das crianças sobre os vírus em geral. Ao longo das entrevistas, buscou-se deixar as crianças confortáveis e livres para expressarem as suas opiniões e visões acerca do que era perguntado.

Todas as entrevistas foram transcritas e a análise das transcrições foi de abordagem qualitativa, que auxilia a compreensão da realidade subjetiva dos entrevistados em suas relações, representações e intencionalidades 27 .

Incluímos, ainda, uma etapa de análise de similitude, que permite identificar a coocorrência entre as palavras de determinado corpus. Essa análise fornece informações sobre a conexão entre as palavras e o nível de relações entre elas, de modo a auxiliar a identificação de conteúdos e categorias de um corpus textual 13,28,29. Para realizá-la, foi utilizado o software IraMuTeQ (http://www.iramuteq.org/), que faz análises estatísticas sobre corpus textuais e gera "árvores máximas", um gráfico que expressa a força de ligação entre as palavras de um corpus 29.

Tendo em vista que se trata de um estudo qualitativo, os resultados não podem ser generalizados para a população de crianças do Rio de Janeiro, mas fornecem informações importantes que podem ajudar a refletir sobre a percepção de crianças acerca da pandemia e os vírus em geral.

\section{Resultados}

Perguntamos às crianças se elas sentiram alguma mudança recente no seu cotidiano. A maioria respondeu que sim, citando que agora tem aulas online, não tem saído de casa e está passando mais tempo com a família. Apenas duas crianças - inicialmente, mais tímidas - responderam que nada mudou. Sobre o motivo das mudanças, as respostas incluíram, geralmente, uma menção ao novo coronavírus, como: "por causa do coronavírus", "porque tem um vírus no mundo", "por causa do corona" e "porque o coronavírus chegou no Brasil, né? Aí começou a ter aglomeração (...) aí eles pediram pra gente ficar em casa”.

$\mathrm{O}$ coronavírus foi diretamente associado à doença por ele causada, e as crianças se referiram aos sintomas ou à relação causal entre o vírus e a doença, como em "[o coronavírus] ...é uma doença que te deixa doente”. A transmissão do coronavírus foi o segundo aspecto mais mencionado no bloco de perguntas sobre a pandemia. Em alguns casos, as crianças utilizavam o termo contágio, mas sempre ressaltando o contato pessoal como a forma de o vírus se espalhar. Em geral, a percepção sobre a transmissão do vírus foi associada ao país de origem, sendo a China o mais mencionado, com uma menção à Itália: “...tudo começou na China, as pessoas da China vieram pra outro país até que chegou aqui no Brasil e um monte de pessoa pegou junto”. É possível perceber também a associação da doença com o consumo de morcego, apontado como o transmissor dessa doença para os seres humanos: "É porque teve uma doença que foi achada pelo morcego (...) a menina ou o homem pediu pra fazer uma sopa com morcego, ai ela pegou e contagiando todas as pessoas".

Em seis explicações, buscou-se definir o coronavírus com linguajar científico, como em "É um vírus da família COVID (...). Que é de uma família de vírus que se evoluíram e agora tá nessa pandemia”. 
O caráter mortal da doença também foi bastante mencionado, em expressões como "É um vírus, parecido com a gripe, só que é capaz de causar morte, seu nariz escorre, você não consegue respirar direito..., ou em "É uma doença que mata pessoas!". Identificamos que as crianças associaram o coronavírus com o ato de ficar em casa, destacando que não se pode sair: "Não pode sair de casa toda hora, só de vez em quando, visitar. Tem gente que até vai no supermercado, tem gente que compra pra chegar em casa".

Com relação aos sentimentos evocados ao falar de COVID-19 ou coronavírus, foram mencionados medo (em 7 relatos), preocupação (7), saudades (5), tristeza (4) e nervosismo (3). Em geral, as crianças relataram medo de se infectar com o coronavírus e preocupação com a possibilidade de sua família adoecer. Isso pode ser exemplificado pelo trecho "Assustada! Com medo de mim [sic] pegar a doença e também com medo dos meus avós morrerem”. A tristeza com a situação de pandemia, tanto pelos casos de morte quanto pelo fato da permanência em quarentena, pode ser ilustrada pela fala " $E u$ me sinto muito triste porque coronavírus é uma doença que muita gente já morreu. coronavírus é muito triste, isso". O sentimento de nervosismo em relação ao vírus foi expresso em trechos como "Sinto um pouco de frio na barriga, porque dá um nervosismo, tipo 'ui, sai pra lá.' Como se fosse um encosto, né?". É válido mencionar o sentimento de incerteza demonstrado por uma das crianças ao dizer que não sabe o que vai acontecer. As crianças também relataram sentir saudades de como a vida era antes da pandemia, especialmente da aproximação afetiva, como abraçar e beijar familiares e amigos: "Saudades (...) de dar beijo nos meus avós, na minha mãe, no meu pai, ficar com a minha prima, visitar meu tio e tia".

$\mathrm{Na}$ árvore de similitude das respostas referentes à pandemia, representação gráfica que evidencia as áreas comuns de um corpus textual, considera-se a ligação entre os termos, sua relação com a vizinhança e a conotação assumida por cada um, em função dos que estão ligados a ele 13,30,31. A análise da ligação entre os termos evocados pelas crianças (Figura 1) indica que a palavra casa foi a que mais estabeleceu conexões, seguida de ficar, sair, pegar, coronavírus e mão. Dentre os elementos diretamente relacionados com casa, destacam-se: álcool em gel, passar, sentir e saudade. Além disso, podemos observar que o ato de ficar em casa está relacionado aos sentimentos evocados pelo distanciamento social e expressa insegurança frente à situação mundial, com destaque para elementos como preocupação, medo, nervoso, morrer e triste.

Destacamos, ainda, a conexão entre coronavírus e doença que, por sua vez, se conectam a termos relacionados à origem do vírus e à rápida evolução da pandemia, como os verbos espalhar e transmitir, associados a elementos como China, morcego e vírus.

$\mathrm{O}$ ato de sair de casa também teve destaque, remetendo à vontade de ir para a rua e a locais habituais ao carioca, como a praia, bem como ao uso da máscara. Também observamos a ligação com o álcool em gel, a saudade de abraçar, de brincar com os amigos e o papel de destaque das mãos, que surgem como fator de contaminação, chamando atenção para a sua boa higienização, com destaque para os termos lavar e contaminar.

No último bloco de perguntas, sobre os vírus em geral, oito crianças associaram o termo a doenças, seja de forma mais explícita ("Eu lembro de pessoas doentes") ou ressaltando o caráter mortal de doenças virais ("Tem que tomar cuidado pra se prevenir porque são doenças que podem levar à morte, como pneumonia, Zika, febre amarela"). Cinco crianças mencionaram transmissão ou contágio, destacando o risco de transmissão: "Alguma doença, alguma coisa que pode transmitir, que a pessoa pode pegar". Duas crianças buscaram descrever a forma do vírus, por exemplo, "Parece um monte de bolinhas!" e "Aquela bolinha verde como um monte de espinho, espinho enfiado". A associação com bactéria apareceu em duas respostas: "Uma bactéria. Vírus e bactéria é basicamente a mesma coisa, né?" e "É que são tipo umas bactérias que se evoluíram...". O cuidado com a higiene também surgiu, com uma criança citando que lembra de "lavar a mão". Duas crianças também relacionaram os vírus com bactérias, utilizando-os como sinônimos: "Vírus é uma bactéria que tem em você, que dá em você e é como se fosse (...). É um tipo de bactéria que dá em você, faz você ficar doente, passar mal (...). Então, se você não cuidar do seu corpo, você vai ter o vírus. No caso a bactéria, que fica no seu corpo". Em uma das entrevistas, a criança perguntou para a entrevistadora se vírus e bactérias eram o mesmo microrganismo.

Por fim, perguntadas sobre o que são os vírus em geral, duas crianças ressaltaram o aspecto científico relacionado à pandemia de COVID-19, ao falarem sobre uma possível vacina: "Com a vacina, se você pegar, tudo bem, que você já vai ter tomado a vacina, mas você vai ter o vírus e vai passar mal e ninguém gosta de ficar doente. Mas o mais importante é você conseguir a vacina, tomar a vacina e sempre tomar as 
Figura 1

Análise de similitude "árvore máxima”, corpus COVID-19.

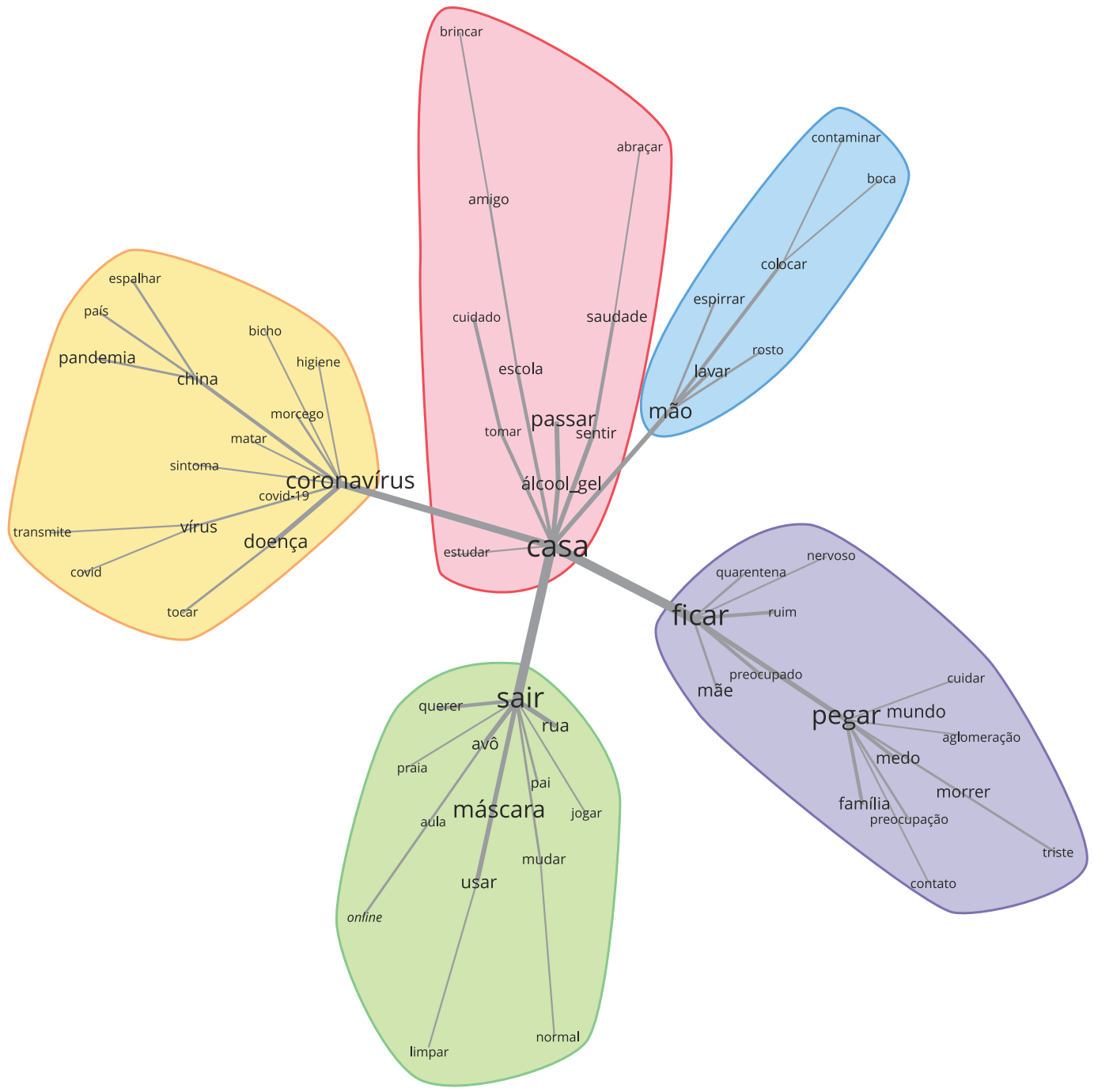

providências que tem que tomar, aí você vai ter menos chances de pegar aquela doença”. E sobre os médicos e cientistas: "contágio, vem cuidados médicos, vem cientistas e pessoas".

Perguntamos às crianças como explicariam o que é um vírus. A associação de vírus com doença foi repetida, com 11 dos entrevistados ressaltando que o vírus é uma doença ou causa sintomas, como em: "Eu ia dizer que o vírus é uma doença" e "Ah, eu explicaria que seria uma doença com vários sintomas (...) tem várias coisas, tipo coronavírus, se você ficar aglomerado você pega, outro vírus se você ficar, sei lá o que, você pega. Entendeu? Aí eu falaria que seria uma doença com vários sintomas”.

A transmissão ou o contágio também apareceram em 11 respostas, como: "É um negócio que contagia outras coisas"; "É um vírus que você pode transmitir pelo ar, pelo espirro, por algum lugar que você toca". Ainda no campo das associações entre vírus e doença transmissível, duas crianças falaram do potencial que os vírus ou as doenças virais têm de matar: "É um bichinho que transmite doenças e às vezes as pessoas podem morrer ou não. Tem que tomar muito cuidado!"; "Vírus é uma coisa que tá matando um monte de gente”. Nesse último caso, a associação dos vírus em geral com o novo coronavírus ficou explícita. 
Formas de prevenção foram mencionadas quatro vezes, como em: "Vírus é uma doença que passa pras outras pessoas, então, se você espirrar, já pode usar máscara, não pode apertar as mãos, só o cotovelo. Não pode abraçar pra não pegar essa doença e se tossir você bota o braço".

Duas crianças ressaltaram o tamanho dos vírus: "o vírus é basicamente um bicho super... basicamente microscópico, que transmite doenças e tem risco de contaminação".

Por fim, três crianças relacionaram os vírus ao mundo tecnológico: "Bom, vírus do computador, né? Só essa que eu sei. Claro que eu conheço algumas outras doenças, mas a que eu mais conheço é a do coronavírus, né, que tá acontecendo e a do vírus do computador, essa as que eu mais sei! A do computador claro que a gente não pega, mas eu conheço mais esses que os outros".

Quando perguntadas se conheciam alguma outra doença transmitida por vírus, as crianças mencionaram 12 vezes diferentes arboviroses: dengue (5 vezes), febre amarela (5), Zika (1) e chikungunya (1). Sete crianças não souberam responder, cinco mencionaram gripe/resfriado, quatro indicaram o coronavírus e uma respondeu pneumonia.

A análise da ligação dos elementos evocados ao se falar de vírus, apresentada na Figura 2, indica que o termo que mais estabeleceu conexões foi doença, seguido de pegar. Dentre os elementos que estão conectados com doença, destacam-se transmitir, contaminação e coronavírus. Observa-se uma atitude apreensiva relacionada a esse elemento, pois os termos têm caráter de alerta e estão ligados à emergência sanitária atual.

Houve, ainda, conexão entre pegar e gripe, ficar/passar e tocar, chamando atenção ao uso de máscara como forma de proteção e ao contato como meio de ficar doente. O elemento mão, novamente, aparece ligado a lavar, indicando o cuidado com a higienização das mãos. A relação com outras doenças infecciosas também apresentou destaque, assim como a conexão estabelecida entre bactérias e vírus.

\section{Discussão}

As crianças entrevistadas não fizeram distinção entre coronavírus e COVID-19, usando os termos como sinônimos, sem diferenciar a doença de seu agente causador. Isso também foi observado nas explicações sobre vírus: algumas crianças responderam que vírus é uma doença, em sintonia com os resultados encontrados por Burbach \& Peterson 14. Crianças mais novas, segundo a literatura, tendem a não diferenciar os sintomas das doenças de suas respectivas causas, já as mais velhas e com maior nível de desenvolvimento, costumam associar as doenças aos germes e infecções 20,32.

A falta de distinção entre vírus e bactérias, usados como se fossem sinônimos, observada em nossos resultados, coincide com os resultados de outras pesquisas, como a de Schuhmacher \& Brum 33, realizada no Brasil com crianças do 60 ano do Ensino Fundamental, na qual observou-se que os estudantes investigados não diferenciavam os microrganismos, considerando todos como sendo bactérias. Essa lacuna de conhecimento tem um impacto importante na saúde pública, ilustrado com dados de survey entre adultos, que mostra que $73 \%$ dos brasileiros acreditam que os antibióticos matam vírus 34 .

As concepções das crianças, de modo geral, estão relacionadas à vida cotidiana, isto é, com o que aprendem com os amigos, na família e na escola, por exemplo, e têm uma grande influência dos meios de comunicação 33. É interessante notar que as Bases Nacionais Comuns Curriculares (2017) não preveem a abordagem de microrganismos até os anos escolares contemplados nesta pesquisa (entre o $20 \mathrm{e}$ 3o anos do Ensino Fundamental). Acreditamos, então, que as crianças procuraram formas de explicar o que é um vírus fazendo associações com base no seu próprio repertório. No geral, tal repertório inclui o conhecimento das bactérias em uma perspectiva de senso comum, aquela que considera as bactérias como "vilãs" da saúde humana ${ }^{33}$. Ao perceberem a gravidade da pandemia do novo coronavírus, a associação com bactérias foi, possivelmente, o caminho encontrado pelas crianças para explicarem do que se trata um vírus.

No que diz respeito aos sentimentos, o medo e a preocupação foram os mais evocados pelas crianças, resultados similares aos da pesquisa de Joffe 24 sobre a representação social da gripe H1N1, e são padrões encontrados recorrentemente em situações de ameaça de doenças infecciosas emergentes 24,35. 


\section{Figura 2}

Análise de similitude "árvore máxima", corpus vírus.

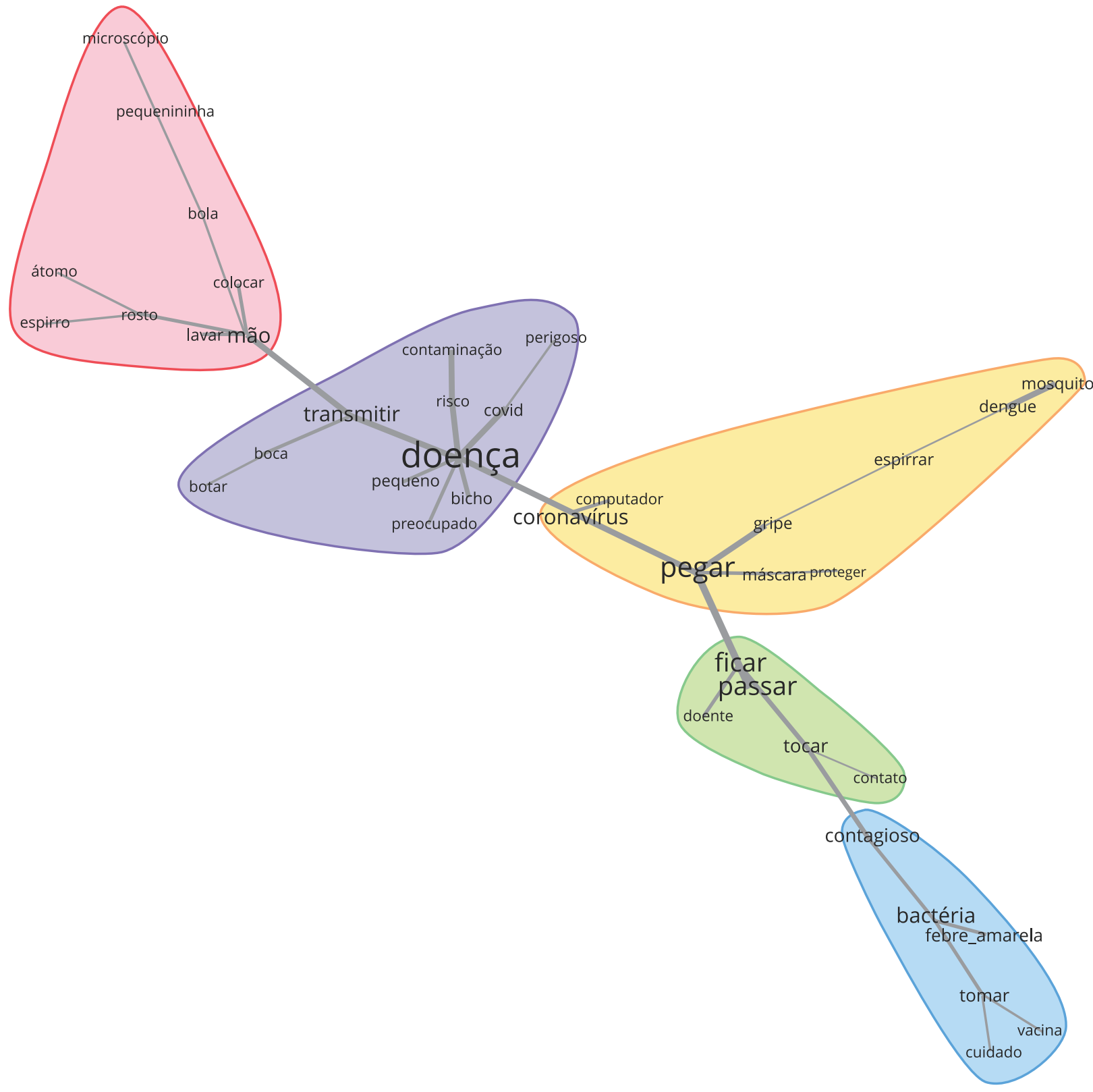

No contexto da COVID-19, especialistas já tinham indicado que a quarentena poderia gerar medo, preocupação, tristeza e estresse nas crianças 8 , como observamos na presente pesquisa e em um estudo realizado com crianças espanholas sobre a pandemia de COVID-19 2.

A respeito das mudanças sentidas no cotidiano, em uma pesquisa de abordagem quantitativa realizada na Argentina 12, apenas 18\% dos adolescentes revelaram se sentir indiferentes e a maior parte deles revelou estar assustada com a situação de pandemia. Em nosso estudo, apenas duas crianças afirmaram que nada mudou, já a maioria delas mostrou-se amedrontada e preocupada. 
Em relação ao sentimento de saudades, principalmente de abraçar e beijar amigos e familiares, é interessante notar que o afeto é uma importante dimensão no desenvolvimento psíquico e cultural das crianças 36 . Esse dado é reforçado por uma pesquisa sobre as consequências psicológicas da pandemia de COVID-19 e do confinamento, realizada na Espanha com jovens e adultos 37, em que os participantes ressaltaram o fato de estarem se abraçando e se beijando menos. Além disso, um estudo feito com crianças espanholas demonstrou que $89 \%$ delas apresentaram alterações comportamentais decorrentes do confinamento 38 . Nesse sentido, a menção que os participantes de nossa pesquisa fizeram à ausência de afeto, somando-se a outros estudos sobre os impactos psicológicos do isolamento social, reforçam a necessidade de as pesquisas levarem a percepção das crianças em consideração 13 .

A preocupação com a família, especialmente com os avós, demonstra que as crianças percebem que o risco pode variar de acordo com a idade. Essa ideia de percepção do risco de acordo com a idade foi corroborada por uma pesquisa quantitativa realizada com italianos entre 18 e 80 anos 10, em que as pessoas mais jovens revelaram não se considerar do "grupo de risco", mas algumas pessoas idosas perceberam um risco maior por causa de sua idade.

Os dados do presente estudo indicam que as crianças relacionam os vírus em geral ao coronavírus, demonstrando que as suas percepções estão pautadas no que elas têm experienciado no período pandêmico. Tanto quando perguntadas sobre os cuidados e formas de prevenção ao novo coronavírus quanto sobre como se contrai um vírus, as crianças mencionaram exaustivamente os cuidados com a higiene, como o ato de lavar as mãos, compras e roupas, e o uso de álcool em gel. Além desses, citaram também, ainda que indiretamente, o distanciamento social, expressando que não se pode ter contato físico ou aglomeração. Todos esses aspectos fazem parte das principais recomendações dos órgãos competentes, como a OMS, para o combate à pandemia 39. Os mesmos aspectos foram observados em outros estudos sobre a pandemia emergente, por exemplo, uma pesquisa com 3.500 adultos, a fim de entender o nível de conhecimento sobre a COVID-19 na Índia, mostrou que 90\% dos respondentes mencionaram estratégias de saúde pública como o uso da máscara e a higiene das mãos 40 .

Por fim, algumas crianças ao mencionar o desenvolvimento de uma vacina e as formas de prevenção ao coronavírus, demonstraram atitude positiva e otimista em relação à ciência e aos médicos e cientistas. Esse otimismo vai ao encontro do resultado de recente enquete de percepção pública da Ciência e Tecnologia (C\&T) no Brasil, em que 73\% dos respondentes revelaram acreditar que C\&T trazem só benefícios ou mais benefícios do que malefícios 32 .

\section{Considerações finais}

Nosso estudo evidenciou que as crianças não estão alheias à pandemia, pois identificamos sentimentos como preocupação e medo, e também que estão compreendendo a gravidade da situação, conscientes das formas de prevenção e de cuidados. Especialmente, identificamos uma preocupação com a transmissão do coronavírus para seus familiares, principalmente para os seus avós. As crianças, portanto, demonstraram entender que as pessoas com mais idade correm mais riscos do que elas e que, assim, poderiam representar um risco aos seus familiares caso entrassem em contato com eles.

Os dados deste trabalho ajudam a elucidar como as crianças percebem os vírus e a pandemia de COVID-19, e demonstram que as percepções desta faixa etária sobre os vírus estão atreladas ao que as crianças têm experienciado no período pandêmico. Nossos resultados sugerem que o contexto e a vivência em situações de doença influenciam o conhecimento e as atitudes das crianças perante a saúde, a doença e a ciência de um modo geral.

No corpus estudado, a percepção das crianças sobre a prevenção da COVID-19 esteve fortemente atrelada ao discurso de prevenção das autoridades de saúde, isto é, elas ressaltaram a importância lavar as mãos, usar álcool em gel e máscaras. Essa percepção, somada às menções a uma possível vacina, demonstram uma atitude positiva e otimismo, por parte das crianças, em relação à ciência e à medicina.

Outro resultado importante diz respeito ao fato de que algumas crianças parecem não fazer distinção entre vírus e bactérias, usando os dois termos como sinônimos, uma lacuna observada também entre adultos na literatura. Isso sinaliza a necessidade de se pensar em estratégias de divulgação científica para as crianças, ressaltando as diferenças entre os microrganismos, especialmente focando na 
educação em saúde, visto que estas percepções, especialmente a percepção do risco, influenciam suas atitudes. Nesse sentido, investigações sobre a percepção das crianças acerca de emergências sanitárias colaboram para a elaboração de estratégias de promoção de saúde mais adequadas para este público, pois são capazes de dialogar com os seus sentimentos e as suas visões.

Notamos que as crianças participantes do estudo se mostraram conscientes dos riscos envolvidos e dos cuidados que devem ser tomados para a prevenção e a contenção do novo coronavírus, como o uso de máscaras, higiene das mãos e distanciamento social. Portanto, estão cientes das principais recomendações dadas pela OMS. Diante desse contexto e dos dados aqui discutidos, enfatizamos a importância de as estratégias e decisões que envolvam e impactem diretamente a vida das crianças, como o retorno às aulas presenciais, levem em consideração seus sentimentos, preocupações e percepções do risco.

O presente estudo, de caráter qualitativo, não permite que seus resultados possam ser extrapolados para todas as crianças cariocas, mas oferece subsídios importantes para se pensar em estratégias de saúde e de divulgação científica para este público, especialmente sobre microrganismos e doenças infecciosas emergentes, como a COVID-19.

\section{Colaboradores}

C. H. Folino e M. V. Alvaro realizaram as entrevistas e a análise dos dados, e participaram na redação do artigo. L. Massarani foi responsável por fazer a proposta geral do estudo, concebendo o desenho metodológico, bem como supervisionou e orientou todas as etapas; participou na redação do texto do artigo. C. Chagas participou na elaboração da proposta geral do estudo e no desenho metodológico, na análise dos dados e na redação do texto do artigo.

\section{Agradecimentos}

Este artigo foi realizado no âmbito do Instituto Nacional de Comunicação Pública da Ciência e Tecnologia, com o apoio do Conselho Nacional de Desenvolvimento Científico e Tecnológico (CNPq) e da Fundação de Amparo à Pesquisa do Estado do Rio de Janeiro (Faperj). Luisa Massarani agradece ao $\mathrm{CNPq}$ pela Bolsa Produtividade $1 \mathrm{~B}$ e à Faperj pela bolsa Cientista do Nosso Estado. Marcela Álvaro agradece à Faperj pela bolsa TCT.

\section{Informações adicionais}

ORCID: Carolina Habergric Folino (0000-00033086-1875); Marcela Vitor Alvaro (0000-00015201-4875); Luisa Massarani (0000-0002-57107242); Catarina Chagas (0000-0002-8698-9563). 


\section{Referências}

1. Universidade Aberta do SUS. Organização Mundial de Saúde declara pandemia do novo coronavírus. https://www.unasus.gov.br/no ticia/organizacao-mundial-de-saude-declarapandemia-de-coronavirus (acessado em 16/ Out/2020).

2. Crokidakis N. COVID-19 spreading in Rio de Janeiro, Brazil: do the policies of social isolation really work? Chaos, Solitons and Fractals 2020; 136:109930.

3. Governo do Estado do Rio de Janeiro. Decreto no 46.970 de 13 de março de 2020. Dispõe sobre medidas temporárias de prevenção ao contágio e de enfrentamento da propagação decorrente do novo coronavírus (COVID-19), do regime de trabalho de servidor público e contratado, e dá outras providências. Diário Oficial do Estado do Rio de Janeiro 2020; 17 mar.

4. Prefeitura da Cidade do Rio de Janeiro. Decreto da Prefeitura do Rio determina medidas para o combate à pandemia do novo coronavírus. https://prefeitura.rio/cidade/decreto-da-pre feitura-do-rio-determina-novas-medidas-pa ra-o-combate-a-pandemia-do-novo-corona virus/ (acessado em 10/Out/2020).

5. Prefeitura do Rio de Janeiro. Rio contra o corona. https://riocontraocorona.rio/plano-deretomada/ (acessado em 10/Out/2020).

6. Linhares MBM, Enumo SRF. Reflexões baseadas na psicologia sobre efeitos da pandemia COVID-19 no desenvolvimento infantil. Estud Psicol (Campinas) 2020; 37:e200089.

7. Grechyna D. Health threats associated with children lockdown in Spain during COVID-19. SSRN 2020; 3 abr. https://pa pers.ssrn.com/sol3/papers.cfm?abstract_ id $=3567670$.

8. Wang G, Zhang Y, Zhao J, Zhang J, Jiang F. Mitigate the effects of home confinement on children during the COVID-19. Lancet 2020; 395:945-4.

9. Glöckner A, Dorrough A R, Wingen T, Dohle $\mathrm{S}$. The perception of Infection risks during the early and later outbreak of COVID-19 in Germany: consequences and recommendations. PsyArXiv 2020; 14 may. https://psyarxiv.com/ $\mathrm{wdbgc/.}$

10. Zanin M G, Gentile E, Parisi A, Spasiano D. A preliminary evaluation of the public risk perception related to the COVID-19 health emergency in Italy. Int J Environ Res Public Health 2020; 17:3024.

11. Bucchi M, Saracino B. Italian Citizens and Covid-19: one month later. Public Understanding of Science Blog 2020; 19 apr. https://sagepus. blogspot.com/2020/04/italian-citizens-andcovid-19-one-month.html.
12. United Nations Children's Fund. COVID-19 rapid assessment. Impact of the COVID-19 pandemic on families with children and adolescents. https://www.unicef.org/argentina/ media/9701/file/Rapid\%20Assessment $\% 20$ on\%20COVD-19\%20impact\%20 on\%20 chil dren\%20and\%20families\%20in\%20Arg-\%20 3rd\%20round.pdf (acessado em 11/Out/2020).

13. Idoiaga N, Berasategi N, Eiguren A, Picaza M. Exploring children's social and emotional representations of the Covid-19 pandemic. Front Psychol 2020; 11:1952.

14. Burbach DJ, Peterson L. Children's concepts of physical illness: a review and critique of the cognitive-developmental literature. Health Psychol 1986; 5:307-25.

15. Solomon GEA, Cassimatis NL. On facts and conceptual systems: young children's integration of their understandings of germs and contagion. Dev Psychol 1999; 35:113-26.

16. Myant KA, Williams JM. Children's concepts of health and illness: understanding of contagious illnesses, non-contagious illnesses and injuries. J Health Psychol 2005; 10:805-19.

17. Helman CG. Limits of biomedical explanation. Lancet 1991; 337:1080-3.

18. Piko BF, Bak J. Children's perceptions of health and illness: images and lay concepts in preadolescence. Health Educ Res 2006; 21:643-53.

19. Millstein SG, Irwin CE. Concepts of health and illness: different constructs or variations on a theme? Health Psychol 1987; 6:515-24.

20. Bibace R, Walsh ME. Children's conceptions of illness. In: Bibace R, Walsh ME, editors. New directions for child development: children's conceptions of health, illness and bodily functions. San Francisco: Jossey-Bass; 1980. p. 3442.

21. Crisp J, Ungerer J A, Goodnow J. The impact of experience on children's understanding of illness. J Pediatr Psychol 1996; 21:57-72.

22. Vacik HW, Nagy MC, Jessee PO. Children's understanding of illness: students' assessments. J Pediatr Nurs 2001; 16:429-37.

23. Schmidt LR, Frohling H. Lay concepts of health and illness from a developmental perspective. Psychology and Health 2000; 15:22939.

24. Joffe H. Public apprehension of emerging infectious diseases: are changes afoot? Public Underst Sci 2011; 20:446-60.

25. Rappaport CR, Fiori WR, Davis C. Psicologia do desenvolvimento. Teorias do desenvolvimento: conceitos fundamentais. São Paulo: Epu Pedagógica e Universitária; 1988. 
26. Ratner B. Statistical and machine-learning data mining: techniques for better predictive modeling and analysis of big data. Hoboken: Taylor and Francis; 2013.

27. Minayo MCS. Estrutura e sujeito, determinismo e protagonismo histórico: uma reflexão sobre a práxis da saúde coletiva. Ciênc Saúde Colet 2001; 6:7-19.

28. Camargo BV, Justo AM. Tutorial para o uso do software Iramuteq. http://www.ira muteq.org/documentation/fichiers/tutori el-portugais-22-11-2018 (acessado em 17/ Out/2020).

29. Gomes AMT, Oliveira DC, SA CP. Social representations of the Brazilian national health care system in the city of Rio de Janeiro, Brazil, according to the structural approach. Rev Latinoam Enferm 2008; 16:122-9.

30. Ratinaud MP. L'analyse de similitude appliqueé aux corpus textueles: les primaires socialistes pour 11election présidentielle française. In: Actes des 11 eme Journées Internationales d'Analyse Statistique des Données Textuelles. Liége: JADT; 2012. p. 687-99.

31. Pontes APM, Oliveira DC, Gomes AMT. The principles of the Brazilian Unified Health System, studied based on similitude analysis. Rev Lationam Enferm 2014; 22:59-67.

32. Perrin EC, Gerrity PS. There is a demon in your belly: children's understanding of illness. Pediatrics 1981; 67:841-9.

33. Schuhmacher E, Brum W. A importância das concepções alternativas na apropriação do conhecimento: a aplicação no estudo de bactérias no Ensino Fundamental e suas implicações para a saúde humana. Revista Areté/Revista Amazônica de Ensino de Ciências 2017; 7:3847.
34. Centro de Gestão e Estudos Estratégicos. Percepção pública da C\&T no Brasil: 2019. Resumo executivo. Brasília: Centro de Gestão e Estudos Estratégicos; 2019.

35. Idoiaga N, Gil de Montes L, Valencia J. Ebola in the public sphere: a comparison between mass media and social networks. Sci Commun 2017; 39:101-24.

36. Lemos ASC. A dimensão do afeto no desenvolvimento cultural da criança [Dissertação de Mestrado]. Campinas: Universidade Estadual de Campinas; 2018.

37. Lasa BMN, Benito GJ, Hidalgo Montesinos MD, Gorostiaga Manterola MA, Espada Sánchez JP, Padilla García JL, et al. Las consecuencias psicológicas de la COVID-19 y el confinamiento. Informe de investigación. https:// www.euskadi.eus/gobierno-vasco/conteni dos/documentacion/doc_sosa_consec_psi que_covid19/es_def/index.shtml (acessado em 15/Out/2020).

38. Espada JP, Orgilés M, Piqueras JA, Morales A. Buenas prácticas en la atención psicológica infantojuvenil ante la COVID-19. Clínica y Salud 2020; 31:109-13.

39. Do Bu EMA. Representações e ancoragens sociais do novo coronavírus e do tratamento da COVID-19 por brasileiros. Estud Psicol (Campinas) 2020; 37:e200073.

40. Raza G, Singh S, Kumar PVS, Dabiru L. Pulse of the pandemic: a sudden surge in scientific attitude during COVID-19 crisis: a preliminary survey report. https://www.anhadindia. com/wp-content/uploads/2020/06/PressRelease-Hindi-English-.pdf (acessado em 17/ Out/2020). 


\section{Abstract}

Although children have been identified as the group least affected by COVID-19 symptoms (even though they are not automatically shielded from the disease or its severe forms), their daily lives have been affected in various ways, including interruption of in-person school activities and contact with classmates, besides other impacts from social isolation and in many cases family financial and health problems. This study aims to understand the perceptions of children in Rio de Janeiro, Brazil towards SARS-CoV-2, COVID-19, and viruses in general, through a qualitative study. We interviewed 20 children via conference services platforms. The findings indicate that children are aware of the risks and necessary precautions for coronavirus prevention, displaying apprehension and fear of catching the disease and transmitting it to their family members. As for viruses in general, we found that their perceptions are related directly to the novel coronavirus, that is, the situation they are dealing with at present. The study provides elements that can help design science dissemination strategies.

COVID-19; Coronavírus; Pandemics; Viruses

\section{Resumen}

A pesar de que los niños sean apuntados como el grupo menos afectado por los sintomas de la COVID-19-aunque no ilesos a la enfermedad y sus formas graves-, su día a día estuvo afectado de varias formas, incluyendo la interrupción de la vida escolar presencial y el contacto con compañeros de clase, además de sufrir impactos relacionados con el aislamiento social y, en muchos casos, problemas financieros y de salud, a los que se tuvieron que enfrentar sus familiares. En este estudio, tenemos como objetivo comprender la percepción de los niños de Río de Janeiro, Brasil, sobre el SARSCoV-2, la COVID- 19 y los virus en general, mediante un estudio cualitativo. Entrevistamos a 20 niños a través de plataformas de servicios de conferencia. Los resultados indican que los niños son conscientes de los riesgos y cuidados necesarios para la prevención del coronavirus, mostrándose aprensivos, con miedo de contraer la enfermedad y contagiársela a sus familiares. En cuanto a los virus en general, observamos que sus percepciones están relacionadas directamente con el coronavirus, esto es, con la situación que están afrontando actualmente. El estudio presenta contribuciones que pueden ayudar en la concepción de estrategias de divulgación científica.

COVID-19; Coronavirus; Pandemias; Virus
Recebido em 22/Out/2020

Versão final reapresentada em 06/Mar/2021

Aprovado em 11/Mar/2021 